\title{
PEMAKNAAN BRAND AWARENESS TAS ELIZABETH SEBAGAI BENTUK IDENTITAS DAN KOMUNIKASI GAYA HIDUP SOSIAL (STUDI KASUS MAHASISWI PENDIDIKAN EKONOMI, FAKULTAS KEGURUAN DAN ILMU PENDIDIKAN, UNIVERSITAS JEMBER)
}

\author{
Karimatul Jumaiyah ${ }^{1}$, Pudjo Suharso ${ }^{1}$, Wiwin Hartanto ${ }^{1}$ \\ Pendidikan Ekonomi, Fakultas Keguruan dan Ilmu Pendidikan, Universitas Jember \\ E-mail: karimatuljumaiyah@gmail.com
}

\begin{abstract}
Abstrak
Kini penampilan menjadi faktor utama dalam menilai status sosial seseorang. Hal yang menyebabkan masyarakat lebih konsumtif karena mereka akan memperbarui penampilan menurut budaya populer dilingkungannya. Budaya populer dilingkungan mahasiswi Pendidikan Ekonomi menggunakan tas Elizabeth, dengan menggunakan tas Elizabeth mahasiswi terlihat lebih percaya diri. Penelitian ini bertujuan untuk mendeskripsikan pemaknaan brand awareness tas Elizabeth sebagai bentuk identitas dan komunikasi gaya hidup sosial (studi kasus mahasiswi Pendidikan Ekonomi, Fakultas Keguruan dan Ilmu Pendidikan, Universitas Jember). Jenis penelitian yang digunakan dalam penelitian ini yaitu penelitian deskriptif dengan pendekatan kualitatif. Metode pengumpulan data menggunakan metode wawancara, metode observasi dan metode dokumentasi. Tahap analisis data, penelitian ini menggunakan reduksi data, penyajian data dan pengambilan kesimpulan. Hasil dari penelitian ini yaitu perbedaan pandangan mahasiswi Pendidikan Ekonomi terhadap tas Elizabeth. Mereka menggunakan tas Elizabeth sebagai penilaian status sosial setiap mahasiswi karena tas Elizabeth memiliki brand image yang baik dilingkungan mahasiswi Pendidikan Ekonomi. Bukan hanya dari brand image, mahasiswi menyadari keunggulan lain yang dimiliki oleh tas Elizabeth. Tas Elizabeth dinilai memiliki kualitas yang baik, model tasnya up to date, memiliki berbagai macam bentuk yang lucu dan tidak mudah rusak. Kesadaran konsumen tentang keunggulan tas Elizabeth inilah menjadi hal terpenting karena tas Elizabeth akan tetap diingat oleh para konsumennya dari segi keunggulan yang dimiliki.
\end{abstract}

Kata kunci: Brand awareness, status sosial, brand image

\section{PENDAHULUAN}

Masyarakat modern dalam menilai status sosial seseorang kini dapat terlihat dari penampilan. Penampilan menjadi poin terpenting yang harus di perhatikan, oleh karena itu agar tersampainya status sosial yang mereka inginkan, maka mereka membutuhkan sebuah media. Tubuh menjadi media untuk mempresentasikan penampilan setiap orang. Menurut Alimi (2011) Tubuh menjadi media untuk perubahan sosial, tubuh juga menjadi media yang efektif untuk mengkomunikasikan dan memperjuangkan gagasan tertentu dalam ruang publik. Fenomena ini menjadikan masyarakat berlomba - lomba untuk memperbaiki dan memperbarui fashion mereka sesuai dengan subkultur yang ada dilingkungan mereka. Gaya berpakaian menjadikan masyarakat menjadi konsumtif. Hal ini terjadi karena mereka ingin membangun identitas sosial dan ingin status sosialnya diakui oleh masyarakat. Apa yang mereka kenakan diperuntukkan tontonan semata. Semua yang dipakai atau yang dimiliki setiap orang, hanyalah diperuntukan untuk totonan semata (Hendrariningrum, R., dkk. 2008). Gaya atau fashion dalam keseharian seseorang bukan hanya dikenakan karena fungsi yang sebenarnya, tetapi semata-mata untuk pencitraan diri mereka masing-masing. Masyarakat akan merasa bangga jika apa yang mereka kenakan ditonton oleh semua orang dan mendapatkan pengakuan atas status sosial yang tinggi. Untuk menunjang penampilan mereka, masyarakat biasanya menggunakan produk atau barang yang terdapat brand, karena secara tidak langsung barang branded dapat meningkatkan status sosial mereka. Masyarakat juga biasanya mengikuti fashion yang menjadi budaya populer dilingkungan mereka. Subkultur sendiri telah menciptakan budaya pop yang biasanya dijalani oleh kelompok - kelompok kaum muda sehingga menjadi populer dilingkungan sendiri (Setiawan, I. 2010). 
DOI:

Fenomena semacam ini juga terjadi lingkungan mahasiswi Pendidikan Ekonomi, dimana subkultur mahasiswi Pendidikan Ekonomi yaitu menggunakan tas Elizabeth. Tampil fashionable menjadi salah satu cara mahasiswi Pendidikan Ekonomi untuk menaikkan citra diri. Peneliti mencari informasi tentang tas branded dimata para mahasiswi. Beberapa mahasiswi yang tidak memiliki tas Elizabeth mengungkapkan bahwa dalam segi ekonomi, seseorang yang menggunakan tas tersebut terlihat memiliki status sosial dari kalangan mampu atau berada. Pendapat dari mahasiswi yang memiliki tas Elizabeth yaitu mereka merasa lebih percaya diri saat menggunakan tas tersebut. Fashion sendiri bagi mahasiswa merupakan media komunikasi status sosial dalam lingkungannya, good looking dapat menjadi dasar penilaian dari orang lain, dengan penampilan fashion yang modis atau good looking, mahasiswa akan memperoleh citra diri yang lebih dimata orang lain (Firdaus, G., dkk. 2016).

\section{METODE PENELITIAN}

Penelitian ini dilakukan di Pendidikan Ekonomi, Fakultas Keguruan dan Ilmu Pendidikan, Universitas Jember yang beralamat di Jalan Kalimantan No. 37, Kampus Tegalboto, Sumbersari, Kabupaten Jember, Jawa Timur 68121. Tempat penelitian ini terdapat permasalahan yaitu penggunaan tas brand Elizabeth dianggap dapat membentuk identitas dan mengkomunikasikan diri oleh mahasiswi sebagai pencintraan diri.

Jenis penelitian yang digunakan dalam penelitian ini yaitu penelitian deskriptif dengan pendekatan kualitatif. Peneliti menggunakan jenis penelitian ini untuk menghasilkan informasi dan memecahkan suatu masalah yang akan diamati. Sumber data dalam penelitian ini ada dua yaitu, informan inti dan juga informan tambahan. Jenis data yang dilakukan dalam penelitian ini yaitu, data primer dan data sekunder. Penelitian ini menggunakan tiga metode dalam pengumpulan data yaitu, metode wawancara tak berstruktur, metode observasi partisipatif dan metode dokumen. Perolehan data dengan berbagai macam cara ini disebut triangulasi (triangulation). Tahap selanjutnya yaitu tahap analisis data, dimana sebuah penelitian akan dikumpulkan menjadi satu kemudian dianalisis untuk dideskripsikan agar sesuai dengan fokus permasalahan yang akan diteliti. Menurut Sugiyono (2017) dalam analisis data kualitatif ada tiga yaitu reduksi data, penyajian data dan pengambilan kesimpulan.

\section{HASIL DAN PEMBAHASAN \\ Hasil Penelitian}

Berdasarkan penelitian yang dilakukan pada mahasiswa Pendidikan Ekonomi, FKIP, Universitas Jember, peneliti telah mendapatkan hasil yang sesuai dengan tujuan penelitian ini yaitu mengetahui pemaknaan brand awareness tas Elizabeth sebagai bentuk identitas dan komunikasi gaya hidup sosial studi kasus pada Mahasiswi Pendidikan Ekonomi, Fakultas Keguruan dan Ilmu Pendidikan, Universitas Jember.

\section{Tubuh Dalam Lingkup Sosial}

Gaya hidup kini menjadi salah satu hal yang penting bagi mahasiswi Pendidikan Ekonomi. Berikut ungkapan menurut PR tentang arti penampilan bagi dirinya: "Kita tampil dilihat oleh orang lain, jadi penampilan itu yang terpenting, soalnya orang pertama kali lihat kita dari penampilan". Setiap orang memperhatikan penampilan demi citra yang ingin dibangun didepan ruang publik. Citra diri yang diinginkan setiap orang pasti berbeda - beda, contohnya citra perempuan cantik yang feminim, perempuan cantik yang dewasa taupun citra diri perempuan yang tomboy. Citra terlahir dari penampilan yang disajikan oleh seseorang seperti yang di ungkapkan YM dan PR, citra yang diharapkan dari pandangan orang lain terhadap penampilan tubuh mereka yaitu perempuan feminim yang enak untuk dipandang. Berbeda dengan informan EM, dia lebih menginginkan citra diri yang lebih muslimah karena EM berhijrah dengan menggunakan pakaian yang menutup aurat dan sopan. Beberapa orang memiliki fashion yang berbeda Saat berada di luar rumah dan didalam rumah. EM, YM dan PR mengatakan jika didalam rumah mereka memakai baju yang nyaman dan ringan untuk didapai dirumah. Saat diluar rumah YM dan PR memilih busana yang sama yaitu glamour dengan make up alis, bedak dan lipstik, sedangkan EM lebih memilih memakai baju muslimah yang menampakkan perempuan muslim yang anggun dan cantik dengan olesan make up bedan dan lipstik 
Jurnal Pendidikan Ekonomi: Jurnal Ilmiah Ilmu Pendidikan, Ilmu Ekonomi, dan Ilmu Sosial ISSN 1907-9990 | E-ISSN 2548-7175 | Volume 13 Nomer 2 (2019)

DOI:

saja. Tubuh memang media yang pas untuk menyampaikan apa yang kita kenakan. Oleh karena itu para mahasiswi menggunkan media ini bukan hanya dari segi fashion saja, tetapi tubuh juga dapat mengkomunikasikan status sosial setiap orang.

\section{Subkultur Identitas Diri Mahasiswi Pendidikan Ekonomi}

Menurut mahasiswi Pendidikan Ekonomi penampilan sangatlah penting karena pertama kali yang dilihat oleh orang lain adalah penampilan seseorang. Oleh karena itu, para mahasiswa akan memperhatikan penampilan dan juga menggunakan barang yang populer dilingkungannya. Berbelanja juga salah satu subkultur yang ada di lingkungan mahasiswi Pendidikan Ekonomi. Mengubah penampilan ataupun untuk menunjang penampilan yang diinginkan, setiap orang harus memiliki modal materi yang cukup banyak. Setiap informan memiliki uang saku dari orang tua kurang lebih 1 juta -4 juta perbulan. Dari uang saku presentase untuk uang belanja para informan pun berbeda beda. EM sekitar 30\%, PR sekitar 25\% dan YM sangat menyukai fashion oleh karena itu YM mengaku lebih banyak menggunakan uang sakunya dengan belanja. Berikut faktor - faktor dalam identitas sosial mahasiswi Pendidikan Ekonomi:

\section{a. Konteks Antarkelompok}

Lingkup mahasiswi Pendidikan ekonomi pasti ada beberapa orang yang memang tidak menggemari tas Elizabeth, ada juga yang fanatik dengan barang tersebut. Hal menarik diungkapkan oleh YM bahwasannya ketika dia bertemu dengan mahasiswi lain yang bukan penyuka dari tas Elizabeth, dia akan meracuni temannya dengan cara menceritakan tas tersebut sesuai dengan pengalamannya.

\section{b. Daya Tarik Ingroup}

Sebagai salah satu yang fanatik terhadap tas Elizabeth, PR mengungkapkan bahwa dalam ingroup setiap pemilik tas Elizabeth didalam lingkungan mahasiswi Pendidikan Ekonomi memiliki pemikiran yang sama, dimana jika mereka bertemu, mereka akan membicarakan model terbaru dari tas tersebut, lalu juga menanyakan harga - harga tas Elizabeth yang sedang populer.

\section{c. Keyakinan Lain}

Perbedaan keyakinan antara kelompok satu dan yang lain pasti terjadi karena perbedaan selera yang dimiliki oleh setiap kelompok. Menurut kelompok yang tidak menggemari tas Elizabeth bahwa seseorang yang memakai tas Elizabeth terlihat biasa saja karena setiap kalangan dapat membeli tas tersebut.

\section{d. Dipersonalisasi}

Setiap orang dikelompok pengguna tas Elizabeth mengaku bahwa mereka menilai setiap anggota di kelompok mereka saat menggunakan tas Elizabeth dan tidak. Menurut EM: "Kalau sudah kumpul dikampus dengan teman - teman yang menggunakan tas Elizabeth biasanya kami menilai penampilan mereka.

\section{Fenomena Gaya Hidup Mahasiswi Pendidikan Ekonomi}

Terdapat tiga fenomena berkembangnya gaya hidup mahasiswi Pendidikan Ekonomi, sebagai berikut:

a. Transformasi Konsumsi

Setiap konsumen pastinya menginginkan transaksi yang memudahkan mereka dalam berbelanja, oleh karena itu kini telah banyak online shop dan maraknya pembangunan mall. Dengan adanya pembangunan mall para konsumen dimudahkan dalam transaksi dan juga kualitas produk pun terjamin. Jember contohnya, baru - baru ini telah dibangun Lippo Mall dan Transmart. YM mengungkapkan bahwa lebih konsumtif sejak dibangunnya mall - mall di Jember dan online shop yang kini memudahkan konsumen dalam membeli barang. Jika ada barang yang diinginkan oleh YM, dia akan membeli barang tersebut bagaimanapun caranya karena jika tidak terbeli YM akan selalu memikirkan barang tersebut.

b. Pengaruh Media 
DOI:

Media biasanya menampilan beberapa gaya hidup trend fashion. Sebelum memutuskan untuk membangun citra dirinya, seseorang akan mencari jati diri, EM dan YM mengungkapkan bahwa mereka memiliki role model untuk fashion mereka. EM memilih Zaskia Sungkar sebagai role model nya sedangkan YM memilih Rachel Vennya. Berbeda pendapat dengan PR, dia mengaku bahwa lebih memilih style fashion nya sendiri tanpa meniru orang lain.

\section{c. Masyarakat Tontonan}

Tahap awal menjadi mahasiswa yaitu beradaptasi dengan lingkungan dengan mencoba hal - hal baru yang populer dilingkungan para mahasiswa. Para mahasiswa mementingkan fashion karena menjadi penilaian sosial dalam lingkungannya. Untuk menunjang penampilan, sedikit atau banyaknya mahasiswi mengetahui soal fashion. PR memperhatikan fashion nya sejak sekolah menengah atas, berbeda pengakuannya dengan YM dan EM, mereka mengungkapkan bahwa mulai mengenal fashion sejak berada di perguruan tinggi karena melihat teman - teman sebaya nya berpenampilan menarik. Hal ini menjadikan mereka termotivasi untuk berpenampilan menarik juga karena ingin teman temannya melihat dan menilai penampilan mereka.

\section{Pemaknaan Brand Awareness Tas Elizabeth \\ a. Identitas Diri}

Subkultur yang ada dilingkungan mahasiswi Pendidikan Ekonomi yaitu menggunakan tas Elizabeth dapat meningkatkan identitas diri mereka. Menurut AR tas Elizabeth tergolong high class di kalangan mahasiswa. PR dan YM pertama kali mengetahui tas Elizabeth dari keluarga, YM mereka baru memulai memakai atau mengkonsumsi tas tersebut dari perguruan tinggi sedangkan PR mengkonsumsi tas Elizabeth sejak duduk dibangku SMA. EM dan DO mengaku bahwa pertama kali mengkonsumsi tas Elizabeth dari melihat teman - teman kampusnya.

\section{b. Komunikasi Gaya Hidup Sosial}

Koleksi tas Elizabeth PR, YM dan EM pun berbeda - beda, YM memiliki koleksi lebih banyak yaitu sekitar 5 tas tetapi 2 dari 5 tas nya menurut YM telah tak layak pakai. PR memiliki 4 tas dan EM baru memiliki 2 tas saja. Berikut alasan para informan menggunakan tas Elizabeth daripada tas yang lain. YM mengungkapkan bahwa:

"Kalau menurut saya tas Elizabeth selain bentuknya lucu trus up to date, dan juga awet. Bukan hanya dari kualitas saja tetapi juga brand image mbak karena kalau dilihat orang pakai tas Elizabeth kayak merasa bangga. Orang lihat saya jinjing pakai tas Elizabeth, saya seneng. Semenjak saya pakai tas Elizabeth, percaya diri saya lebih tinggi, karena saya pakai barang mahal. Saya juga sering mendapatkan pujian dari teman - teman".

EM sampai saat ini dia telah memiliki 2 tas Elizabeth dan dia memiliki pendapat yang sama dengan YM tentang tas Elizabeth: "Saya mengetahui tas Elizabeth dari teman kuliah. Saya memilih tas Elizabeth karean kualitas sesuai dengan citra merek, kualitas tasnya bagus. Menurut saya Elizabeth sudah punya merek yang baik". Informan ketiga dalam penelitian ini pun memiliki alasan kuat mengapa PR memilih mengkonsumsi tas Elizabeth, berikut ungkapan PR: "Saya memilih tas Elizabeth soalnya model nya bagus lalu harganya juga masih dapat dijangkau oleh mahasiswa. Brand image Elizabeth juga baik, tapi juga selain itu kalau dipakai cocok".

Keunggulan tas Elizabeth yang disadari oleh mahasiswi Pendidikan Ekonomi yaitu tas tersebut memiliki brand image yang baik dilingkungan mahasiswi Pendidikan Ekonomi, kualitas yang dimilikipun bagus, memiliki banyak model yang selalu up to date dan juga bentuk tas yang lucu lucu, cantik dan unik. Kesadaran terhadap keunggulan tas Elizabeth ini lah yang menjadikan mahasiswi Pendidikan Ekonomi mengkonsumsi tas tersebut karena kebutuhan bukan lagi keinginan.

\section{Pembahasan}

\section{Tubuh Dalam Lingkup Sosial}

PR dan YM dalam ruang publik di lingkungan mahasiswa Pendidikan Ekonomi sendiri menginginkan citra diri perempuan yang feminim dan enak untuk dipandang. Sedangkan informan EM memiliki pandangan lain yaitu dia lebih menginginkan citra diri yang lebih muslimah karena EM berhijrah dengan menggunakan pakaian yang menutup aurat dan sopan. Menurut Alimi (2011) faktor penting dalam bergaya salah satunya yaitu tubuh dalam ruang publik, dimana tubuh dalam ruang 
Jurnal Pendidikan Ekonomi: Jurnal Ilmiah Ilmu Pendidikan, Ilmu Ekonomi, dan Ilmu Sosial ISSN 1907-9990 | E-ISSN 2548-7175 | Volume 13 Nomer 2 (2019)

DOI:

publik yaitu lingkup ruang publik yang dapat dilihat dari tubuh, pembentukan tubuh dan identitas sosial yang dibangun oleh seseorang. Setiap simbol alamiah berasal dari tubuh dapat memuat pemaknaan sosial, setiap budaya dan lingkungan membuat seleksinya sendiri dari wilayah simbolisme tubuh (Synnot, A. 2016).

\section{Subkultur Identitas Diri}

Mahasiswi Pendidikan Ekonomi sangat memikirkan penampilan karena penampilan sangatlah penting karena pertama kali yang dilihat oleh orang lain adalah penampilan seseorang. Oleh karena itu mereka rela untuk menjadi lebih konsumtif demi meningkatkan status sosial dalam lingkungannya. Berbelanja juga populer di lingkungan mahasiswi Pendidikan Ekonomi. Setiap informan memiliki uang saku dari orang tua kurang lebih 1 juta -4 juta perbulan. Dari uang saku mereka presentase uang yang digunakan belanja pun berbeda - beda. EM sekitar 30\%, PR sekitar 25\% dan YM sangat menyukai fashion oleh karena itu YM mengaku lebih banyak menggunakan uang sakunya dengan belanja.

Menurut Sarwono (1999) identitas sosial seseorang dapat membentuk konsep diri dan dapat menepatkan dirinya pada posisi tertentu dalam hubungan - hubungan sosial. Berbelanja adalah salah satu aktivitas pengisi waktu luang yang populer dilingkungan masyarakat modern (Storey, J. 2006). YM, PR dan EM mengungkapkan bahwasannya ketika mereka bertemu dengan mahasiswi lain yang bukan penyuka dari tas Elizabeth, dia akan meracuni temannya dengan cara menceritakan tas tersebut sesuai dengan pengalamannya. YM juga mengatakan bahwa ada temannya menggemari tas Elizabeth karena cerita pengalaman YM yang sudah lama menggunakan tas tersebut. Perspektif identitas sosial didalam psikologi sosial biasanya dipandang sebagai analisis hubungan antar kelompok dalam skala besar kategori sosial, yang bertumpu pada kognitif dan konsep diri definisi kelompok sosial (Hogg, M.L., dkk, 2004).

PR, YM dan EM mengungkapkan bahwa dalam ingroup setiap pemilik tas Elizabeth didalam lingkungan mahasiswi Pendidikan Ekonomi memiliki pemikiran yang sama, dimana jika mereka bertemu, mereka akan membicarakan model terbaru dari tas tersebut, lalu juga menanyakan harga harga tas Elizabeth yang sedang populer. Menurut Hogg, M.L., dkk (2004) bahwa grup sosial adalah kumpulan lebih dari dua orang yang memiliki identitas sosial yang sama, mereka mengidentifikasi diri mereka dengan cara yang sama dan memiliki definisi yang sama tentang siapa mereka, apa atribut mereka miliki, dan bagaimana mereka berhubungan dengan kelompok luar yang berbeda dengan mereka. Perbedaan keyakinan antara kelompok satu dan yang lain pasti terjadi karena perbedaan selera yang dimiliki oleh setiap kelompok. Oleh karena itu DO mengatakan bahwa pemilih tas Elizabeth terlihat biasa saja karena semua kalangan dapat membeli tas tersebut, namun menurut IL dan AR bahwa pemilik tas Elizabeth memiliki status sosial yang tinggi. Perbedaan antara kelompok untuk membangun prototipe ingroup dan outgroup itu memaksimalkan entitativitas dan keterpisahan antar kelompok dan kejelasan dalam konteks khusus identitas sosial (Hogg, M.L., dkk, 2004). Pengakuan EM tentang kelompok pengguna tas Elizabeth bahwa jika pengguna tas Elizabeth kumpul dikampus biasanya mereka menilai penampilan mereka. Sependapat dengan EM, YM pun juga mengungkapkan bahwa menilai satu sama lain itu sudah hal yang biasa karena didalam kelompok pengguna tas Elizabeth memiliki pembicaraan yang nyambung jadi menilai menjadi hal yang biasa. Proses dimana anggota kelompok tidak hanya berbagi dalam hal atribut tetapi juga terlibat dalam aksi sosial, dimana penilaian tentang apa yang dipakai oleh setiap individu di dalam sebuah kelompok (Hogg, M.L., dkk, 2004).

\section{Fenomena Gaya Hidup}

Fashion kini menjadi tolak ukur masyarakat modern dalam menilai seseorang. Lingkungan mahasiswi Pendidikan Ekonomi pun memiliki subkultur berbelanja. YM mengungkapkan bahwa lebih konsumtif sejak dibangunnya mall - mall di Jember dan online shop yang dapat memudahkan YM dalam berbelanja. Perubahan gaya hidup masyarakat modern salah satunya yaitu transformasi konsumsi yang kini lebih konsumtif, hal ini bisa terjadi karena maraknya pembangunan mall dan juga online shop yang tersebar di seluruh Indonesia (Hendrariningrum, R., dkk. 2008).

Perkembangan media juga menjadi perubahan gaya hidup mahasiswi Pendidikan Ekonomi.Informan YM sering kali meniru gaya selebgram karena menurut dia semua yang dipakai para selebgram terlihat bagus dan mewah. EM dan YM mengungkapkan bahwa memiliki role model 
Jurnal Pendidikan Ekonomi: Jurnal Ilmiah Ilmu Pendidikan, Ilmu Ekonomi, dan Ilmu Sosial ISSN 1907-9990 | E-ISSN 2548-7175 | Volume 13 Nomer 2 (2019)

DOI:

untuk fashion mereka. EM memilih Zaskia Sungkar sebagai role model nya sedangkan YM memilih Rachel Vennya. Berbeda pendapat dengan PR, dia mengaku bahwa lebih memilih style fashion nya sendiri tanpa meniru orang lain. Perkembangan industri media seperti media cetak ataupun media sosial menjadi ladang persamaian gaya hidup kaula muda, melalui media para remaja dapat mencari identitas dan citra diri yang diinginkan (Hendrariningrum, R., dkk. 2008).

YM dan EM mengungkapkan bahwa mulai mengenal dan memperhatikan fashion sejak berada di perguruan tinggi karena melihat teman - teman sebaya nya berpenampilan menarik. Mahasiswi Pendidikan Ekonomi mementingkan fashion untuk menunjang identitas sosial mereka. Penampilan adalah segalanya, dimana desain dalam produk yang dipakai adalah yang terpenting hal ini membuat setiap orang ingin menjadi pusat perhatian dan ditonton (Hendrariningrum, R., dkk. 2008).

\section{Pemaknaan Brand Awareness}

Salah satu informan mengungkapkan dengan menggunakan barang branded dapat menunjang penampilan seseorang, menurut AR barang branded dapat menunjang citra seseorang. Karena dengan barang - barang branded seseorang bisa mengkomunikasikan diri mereka di hadapan orang lain. Tas Elizabeth memiliki brand image yang baik dilingkungan mahasiswi Pendidikan Ekonomi. Oleh karena itu kebanyakan mahasiswi Pendidikan Ekonomi menggunakan tas Elizabeth demi meningkatkan identitas diri mereka didepan teman - temannya. Namun setelah menggunakan tas Elizabeth para informan menyadari keunggulan - keunggulan yang dimiliki tas Elizabeth. Barang branded adalah suatu barang yang memberikan manfaat, baik secara fungsional maupun emosional yang sesuai dengan ekspektasi para pelanggan (Hasson, B. 2008).

Keunggulan tas Elizabeth yang disadari oleh mahasiswi Pendidikan Ekonomi yaitu tas Elizabeth ini memiliki brand image yang baik dilingkungan mahasiswi Pendidikan Ekonomi, kualitas yang dimiliki bagus, memiliki banyak model yang selalu up to date dan juga bentuk tas yang lucu lucu, cantik dan unik. Kesadaran terhadap keunggulan tas Elizabeth ini lah yang menjadikan mahasiswi Pendidikan Ekonomi mengkonsumsi tas tersebut karena kebutuhan bukan lagi keinginan. Mahasiswi merasakan kepuasan dalam menggunakan tas Elizabeth. Kesadaran terhadap suatu brand menjadikan konsumen akan menjatuhkan pilihan kepada barang branded tertentu dan para konsumen akan mengejar kepuasan dalam menggunakan suatu brand (Pratomo, A. 2013). Kesadaran merek (brand awareness) dapat diartikan sebagai kekuatan sebuah merek, dimana merek tersebut dapat diingat oleh konsumen dan dapat dilihat dari kemampuan konsumen untuk mengidentifikasi merek dalam berbagai kondisi (Ghealita, V., dkk. 2015).

\section{PENUTUP}

Berdasarkan hasil dari penelitian yang dilakukan, peneliti menyimpulkan bahwa kebanyakan mahasiswi Pendidikan Ekonomi, FKIP, UNEJ memiliki pandangan yang berbeda terhadap brand tas Elizabeth. Barang yang dapat meningkatkan status sosial dikalangan mahasiswi Pendidikan Ekonomi, FKIP, UNEJ yaitu salah satunya barang dengan brand Elizabeth. Para informan mengungkapkan bahwa pertama kali mengkonsumsi tas Elizabeth sejak memasuki perguruan tinggi karena melihat teman - teman yang lain juga mengkonsumsi tas tersebut. Makna brand awareness tas Elizabeth dalam lingkungan mahasiswi Pendidikan Ekonomi yaitu mahasiswi Pendidikan Ekonomi menyadari keunggulan - keunggulan yang dimiliki tas Elizabeth. Tas Elizabeth memiliki brand image yang baik dikalangan mahasiswi, kualitas yang dimiliki oleh tas ini bagus, model tasnya up to date dan juga memiliki berbagai macam bentuk yang lucu dan cantik. Oleh karena itu, mahasiswi Pendidikan Ekonomi kini mengkonsumsi tas Elizabeth bukan hanya memikirkan keinginan mereka tetapi tas tersebut telah menjadi sebuah kebutuhan.

\section{DAFTAR PUSTAKA}

Alimi, Moh Yasir. 2011. Tubuh, Ilmu Sosial dan Ruang Publik Masyarakat Muslim. Forum Ilmu Sosial. $38(1)$.

Firdaus, G., dkk. 2016. Fashion Sebagai Komunikasi Identitas Sosial Mahasiswa FKIP UNS. Tidak dipublikasikan. Skripsi. Surakarta: Universitas Sebelas Maret. 
DOI:

Ghealita, V dan Retno S. 2015. Pengaruh Brand Awareness Terhadap Keputusan Pembelian AMDK Merek Aqua (Studi Pada Masyarakat di Kota Bandung). 4 (1).

Hasson, B. 2008. Fashion Branding 7 Jurus Sukses Branding Bisnis MLM Fashion. Jakarta: PT. Gramedia Pustaka Utama.

Hendrariningrum, R dan M. Edy Susilo. 2008. Fashion dan Gaya Hidup: Identitas dan Komunikasi. Jurnal Ilmu Komunikasi. 6 (2).

Hogg, M.L., dkk. 2004. The Social Identity Perspective Intergroup Relations, Self-Conception, and Small Groups. Sage Journal. 35 (3): 246 - 276.

Pratomo, A. 2013. Pemaknaan Brand Awareness Sebagai Bentuk Identitas dan Gaya Hidup Kelas Menengah Kota Studi Kasus: Brand Awareness Sepatu Kickers. Depok: Universitas Indonesia.

Sarwono, S.W. 1999. Psikologi Sosial. Jakarta: PT. Balai Pustaka.

Setiawan, I. 2010. Yang Muda Yang Bertingkah: Konsumsi, Resistensi, dan Kreativitas Kaum Muda dalam Budaya Pop. Universitas Jember.

Sugiyono. 2017. Metode Penelitian Kualitatif. Bandung : Alfabeta.

Storey, J. 2006. Cultural Studies dan Kajian Budaya Pop. Yogyakarta: Jalasutra.

Synnott, A. 2016. Tubuh Sosial Simbolisme, Diri, dan Masyarakat. Yogyakarta: Jalasutra. 